\title{
RESEARCH
}

\section{Priming Is a Suitable Strategy to Enhance Resistance Towards Leaf Rust in Barley}

\author{
Gwendolin Wehner, ${ }^{1}$ Doris Kopahnke, ${ }^{1}$ Klaus Richter, ${ }^{1}$ Steffen Kecke, ${ }^{2}$ Adam Schikora, ${ }^{3}$ and Frank Ordon ${ }^{1, \dagger}$ \\ ${ }^{1}$ Julius Kühn-Institut (JKI), Institute for Resistance Research and Stress Tolerance, Erwin-Baur-Str. 27, 06484 \\ Quedlinburg, Germany \\ 2Julius Kühn-Institut (JKI), Central Data Processing Group, Erwin-Baur-Str. 27, 06484 Quedlinburg, Germany \\ ${ }^{3} J u l i u s$ Kühn-Institut (JKI), Institute for Epidemiology and Pathogen Diagnostics, Messeweg 11-12, 38104 \\ Braunschweig, Germany
}

Accepted for publication 07 February 2019.

\begin{abstract}
Priming allows plants to respond faster and stronger to abiotic or biotic stresses. Leaf rust (Puccinia hordel) is an important pathogen of barley (Hordeum vulgare), for which resistance genes are known, but mostly overcome. Therefore, the aims of this study were (i) to establish a priming system in barley, based on bacterial $\mathrm{N}$-acyl homoserine lactone ( $\mathrm{AHL}$ ), and (ii) to get information on the effect of priming on the reaction to leaf rust. Plants were inoculated with bacteria, i.e., Ensifer meliloti with repaired expR copy, producing the oxo-C14-homoserine lactone (AHL) and an $E$. meliloti strain carrying the attM lactonase gene from Agrobacterium tumefaciens, which cleaves the AHL and acts here as negative control. After three bacterial inoculations, plants were
\end{abstract}

ABSTRACT challenged with $P$. hordei strain I-80 at the three leaves stage. Twelve days after infection, scoring of the leaf area diseased and the infection type was conducted followed by the calculation of the relative susceptibility. First results indicate a significantly $(P<$ 0.001 ) higher resistance level to $P$. hordei after inoculation with E. meliloti. Furthermore, significant $(P<0.001)$ differences were detected between the accessions tested for priming efficiency, which can be the basis to screen a larger set of barley accessions to detect quantitative trait loci or candidate genes involved in priming.

Keywords: agriculture, microbiome, plant pathology.
Induced systemic resistance (ISR) is one of many mechanisms of plants to cope with their environment, as they are not able to escape unfavorable conditions. Typically, ISR is induced by plant-associated beneficial microbes, which are influenced by the plant itself (Pieterse et al. 2014; Zhalnina et al. 2018), and the enhanced defense mechanisms serve against a broad range of pathogens (Mauch-Mani et al.

\section{Corresponding author: F. Ordon; frank.ordon@julius-kuehn.de}

Author Contributions: G.W. conducted all experiments, including statistical and bioinformatics analyses and mainly wrote the manuscript. D.K. and K.R. contributed to establish $P$. hordei infection and E. meliloti inoculation methods, respectively. S.K. designed the formula for calculation of relative susceptibility and A.S. provided bacterial strains and protocols for priming. A.S. and F.O planned and designed the research. All authors approved the final manuscript.

Funding: This study was funded by the German Federal Ministry of Education and Research (BMBF) (grant FKZ 031B0196C) in the scope of the Plant2030 perspective.

The author(s) declare no conflict of interest.

Copyright (C) 2019 The Author(s). This is an open access article distributed under the CC BY 4.0 International license.
2017). Often beneficial microbes are located in the rhizosphere, such as the Gram-negative rhizobacteria, controlling their population size by the signal molecule $\mathrm{N}$-acyl homoserine lactone (AHL). These signaling molecules were described already as priming inducers (Mathesius et al. 2003; Parsek and Greenberg 2000; Schikora et al. 2011; Schuhegger et al. 2006; Viswanath et al. 2016). AHL molecules vary in the length of the acyl chain, ranging from 4 to 18 carbon atoms and thereby can be clustered in long and short chain AHLs which can have different effects on plants (Schikora et al. 2016), for instance C6-homoserin-lactone (HSL) and C8-HSL triggers growth promotion in Arabidopsis thaliana (Liu et al. 2012; Schenk et al. 2012), whereas C12-HSL and C14-HSL induces systemic resistance in different crops (Hernández-Reyes et al. 2014). AHL-producing bacteria belong to Agrobacterium, Erwinia, Pantoea, Pseudomonas, Ralstonia, Rhizobium, and Xanthomonas (Cha et al. 1998; Viswanath et al. 2015). The AHL-producing rhizosphere bacterial communities may induce so called primed state in plants, in which the resistance of plants against biotic and abiotic stress factors is increased (Schikora et al. 2016; Viswanath et al. 2016). Moreover, there is evidence for an epigenetic control of the primed state (Beckers et al. 2009; Conrath et al. 2002) and memory of plants 
regarding priming (Martinez-Medina et al. 2016; Mauch-Mani et al. 2017). Nevertheless, the molecular mechanisms of priming are still unclear (Mhlongo et al. 2018), but the salicylic acid/oxylipindependent pathway inducing stomatal defense response and cell wall strengthening is a signaling cascade related to AHL-priming (Schenk et al. 2014; Schenk and Schikora 2015).

During the last years first results on priming effects based on AHLproducing bacteria were published (Schikora et al. 2016; Viswanath et al. 2016), for instance the priming system in tomato, in which ISR was introduced by Serratia liquefaciens against the necrotrophic pathogen Alternaria alternata (Schuhegger et al. 2006), the use of Serratia plymuthica in cucumber, tomato, and bean for ISR against the necrothrophic pathogens Pythium aphanidermatum and Botrytis cinerea (Pang et al. 2009), as well as the use of Ensifer meliloti as priming inducer in barley, wheat, and tomato against the biotrophic pathogens Blumeria graminis, Puccinia graminis, and Phytophthora infestans (Hernández-Reyes et al. 2014). In addition, chemical AHLs are widely used as priming inducers especially in the model plant Arabidopsis thaliana. The authors studied resistance against biotrophic pathogens (Schikora et al. 2011), but also induced growth promotion on shoot and root (Liu et al. 2012; Ortiz-Castro et al. 2008; Schenk et al. 2012; Zhao et al. 2015) and phytohormone changes (von Rad et al. 2008). Furthermore, there are other priming possibilities, like priming by plant growth promoting rhizobacteria and fungi (Mauch-Mani et al. 2017; Singh et al. 2016), as well as other microbe derived stimuli, for example liposaccharides (Newman et al. 2007), phenazine-1-carboxylic acid (Lohitha et al. 2016), and $\beta$-aminobutyric acid (Conrath et al. 2002, 2006; Mauch-Mani and Mauch 2005; Zimmerli et al. 2000).

In summary, the beneficial effects of microbiome rhizobacteria gives the plants a surplus profit for plant health and growth. Thus, in recent years bacterial biofertilizers were developed for more sustainable agriculture and forestry (García-Fraile et al. 2015). As the first publications on AHL-priming in barley (Hordeum vulgare L.) concerning resistance against Blumeria graminis (Hernández-Reyes et al. 2014; Schikora et al. 2011) and plant growth promoting effects (Han et al. 2016), barley seems to be a suitable crop to study priming. Therefore, in this study, barley was used, which is one of the most important cereals worldwide (FAOSTAT 2016), as a model to conduct AHL-priming triggered with Ensifer meliloti and leaf rust (Puccinia hordei Otth.), which is one of the most important diseases of barley (Park et al. 2015), was used as a challenger. The aim of this study was to assess whether Ensifer meliloti-induced priming in barley (Hernández-Reyes et al. 2014) is effective against the biotrophic pathogen Puccinia hordei and whether genetic differences with respect to priming exist in barley.

Puccinia hordei in barley can lead to yield losses up to $60 \%$ (Cotterill et al. 1992) and a reduction of malting quality (Murray and Brennan 2010). Because in Europe the sexual proliferation by Ornithogalum umbellatum is not essential, the asexual proliferation by uredospores is the main dissemination strategy (Anikster and Wahl 1979). Due to the high yield losses it is essential for consumer and environmentally friendly barley production to control leaf rust infection. This is mainly achieved by using the resistance genes RphlRph26 (Kavanagh et al. 2017; Park et al. 2015; Yu et al. 2018; Ziems et al. 2017b). Because most are race specific, many of these resistance genes have been overcome and the primary gene pool of barley is to some extent depleted for new resistance genes (Niks et al. 2000). Therefore, priming in contrast to chemical plant protection may offer an alternative to enhance resistance against Puccinia hordei in barley.

\section{MATERIALS AND METHODS}

Plant material. In order to identify the genetically most diverse accessions for this study, five accessions out of a worldwide set of diverse barley accessions were selected. To achieve this the set of 224 spring barley accessions (called Genobar set) described in Pasam et al. (2012) were genotyped with the 9k iSelect Chip (Comadran et al. 2012). Based on 6,355 polymorphic single nucleotide polymorphisms (SNP), filtered by $5 \%$ minor allele frequency, $12.5 \%$ heterozygous SNPs and 10\% missing values, a modified Rogers distance matrix (Wright 1968) was calculated according to Reif et al. (2005) in R Studio (RStudio Team 2015). Based on these results, a principal coordinate analysis (PCoA) was conducted (Gower 1967) using the stats package of R (Fig. 1), and five k-medoids were calculated (Kaufman and Rousseeuw 2005; Reynolds et al. 2006) with the prabclus package of R, to identify the five genetically most diverse accessions, i.e., BCC768, BCC1589, BCC1415, BCC436, and HOR7985 (Fig. 1). In addition, Golden Promise and Morex were used as standards.

Experimental design. The seven selected accessions were tested for their priming capacity in two pot experiments, compromising nine replications with three plants per pot each. Pots of 0.2 liter were filled with soil substrate (Fruhstorfer type T) and arranged in a split plot design in the greenhouse at night/day temperatures of $18^{\circ} \mathrm{C} /$ $22^{\circ} \mathrm{C}$ with additional lighting for $10 \mathrm{~h}$. Two days after germination of seeds on a wet filter paper, the seedlings were planted in soil. The plants were treated with $3.5 \mathrm{ml}$ of bacteria suspension $\left(10^{8} \mathrm{CFU} / \mathrm{ml}\right)$ three times at 2, 8, and 14 days after planting (dap), respectively. Bacterial suspension was generated out of a bacterial preculture consisting of tryptone-yeast medium described in Stein and Schikora (2018). This preculture was centrifuged at 5,000 rpm for $10 \mathrm{~min}$, and bacterial pellets were resuspended in $10 \mathrm{mM} \mathrm{MgCl}_{2}$ until a density of $\mathrm{OD}_{600}=0.1$, representing approximately $10^{8}$ colony forming units (CFU) per ml, was reached. Bacterial strains used here were the repaired Ensifer meliloti natural mutant $\exp R^{+} c h$ producing oxo-C14-HSL and Ensifer meliloti carrying the lactonase gene attM from Agrobacterium tumefaciens on the plasmid pBBR2-attM, which cleaves the produced AHL and acts as a negative control (Zarkani et al. 2013). Because it is known from comparable experiments of Schikora et al. (2011) that the Ensifer meliloti triggered priming is AHL-dependent, a mock variant was

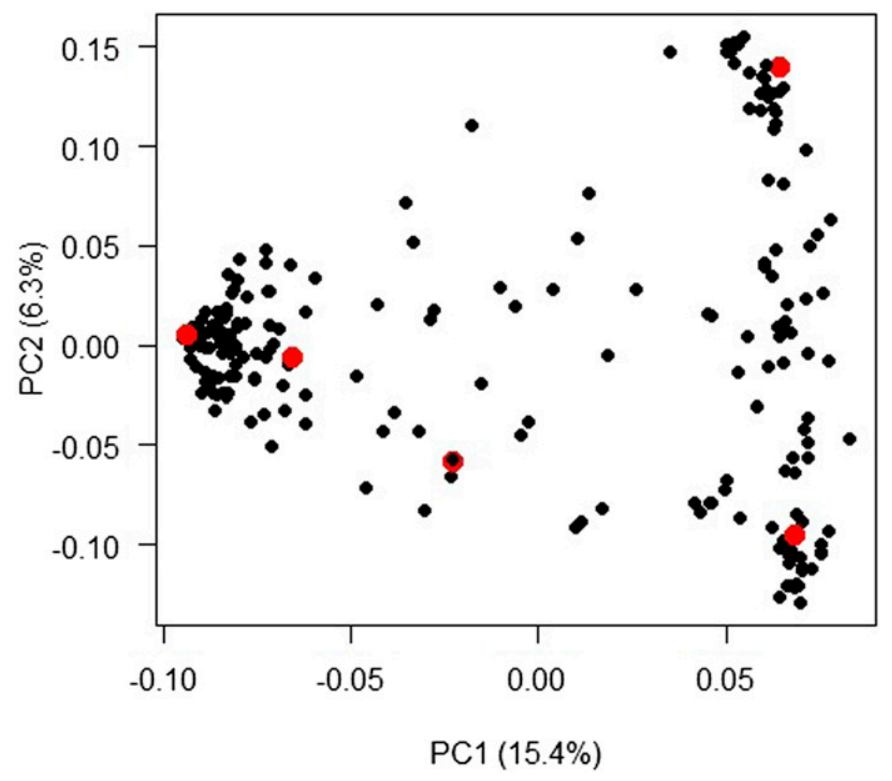

Fig. 1. Principal coordinate analysis of the spring barley Genobar collection (Pasam et al. 2012). Selected accessions are highlighted in red. PC1 and PC2 refer to the first and second principal coordinates, respectively. 
not included in our experiments. After three inoculation events, plants were infected with Puccinia hordei isolate I-80 at the three leaves stage, 16 dap. Twenty-five milligrams of Puccinia hordei uredospores (mixed with white clay 1:3) was distributed continuously to 24 pots using a powder atomizer, after application of a $0.01 \%$ Tween 20 solution to support adhesion of uredospores to the leaves. Plants were incubated in containers, covered, and darkened for $24 \mathrm{~h}$. Twelve days after infection (dai), scoring of the percentage of leaf area diseased (Moll et al. 2000) and infection type (Levine and Cherewick 1952) were conducted, hereafter named Puccinia hordei (\%) and Puccinia hordei (scores), respectively. To generate numeric data out of score numbers, the method from Dracatos et al. (2016) was used. Out of the quantitative (Puccinia hordei \%) and qualitative (Puccinia hordei scores) scoring, the relative susceptibility was calculated on the basis of a random distribution of natural logarithms:

Relative susceptibility $=0.2 \times \ln (P$. hordei $\%)+(P$. hordei scores $)$

Based on the importance and genetic background of the Puccinia hordei (scores), this trait is included with 100\%, whereas Puccinia hordei (\%) is included by $20 \%$ to exclude errors due to inoculation and scoring. In previous studies not focusing on priming, infected leaf area and infection type were analyzed separately (Silvar et al. 2010; Singh et al. 2015, 2017; Ziems et al. 2017a), but with regard to priming most accessions will be ranked differently when only one of the traits is taken into account. For the ranking of accessions, the priming efficiency was calculated by the difference of relative susceptibility for priming with $\operatorname{attM}$ and $\operatorname{expR^{+}} c h$ :

$$
\begin{aligned}
& \text { Priming efficiency }=\text { relative susceptibility }(a t t M) \text { - } \\
& \text { relative susceptibility }\left(\exp R^{+} c h\right)
\end{aligned}
$$

Statistical analysis. Using the statistic software of R Studio Version 1.1.442 (RStudio Team 2015), descriptive statistics were calculated using the package pastecs as well as the package agricolae for least significant differences and grouping of accessions. Analysis of variances was calculated by applying a linear mixed effects (lme) model in the nlme package of R. Thus, effects of priming $\left(\alpha_{i}\right)$, accessions $\left(\beta_{j}\right)$, and the interaction $(\alpha \beta)_{i j}$ were set as fixed effects, whereas plant, replication, and experiment were defined as random effects $\left(r_{k}\right)$, with error $\left(b_{i k}\right)$ of the $i$ th main plot in $k$ th block and the subplot error $\left(e_{i j k}\right)$ :

$$
y_{i j k}=\mu+\alpha_{i}+\beta_{j}+(\alpha \beta)_{i j}+r_{k}+b_{i k}+e_{i j k}
$$

where $y$ is the trait of interest with $i$ th level of priming and $j$ th level of accession in $k$ th block and the general mean $\mu$. Out of the two experimental replications, a repeatability $\left(r^{2}\right)$ was calculated out of variance components $(V)$ using the formula of heritability without effects of location:

$$
r^{2}=V_{\beta} /\left(V_{\beta}+V_{\beta \gamma} / \gamma+V_{e} / r \gamma\right)
$$

where $\gamma$ is the experiment, $r$ the replication, and $V_{e}$ the total error variance.

\section{RESULTS}

The experiments revealed decreased mean values for Puccinia hordei (\%), Puccinia hordei (scores), and the relative susceptibility comparing priming with the Ensifer meliloti attM to $\exp R^{+} \mathrm{ch}$ (Table 1, Fig. 2). Standard deviation between 0.106 and 5.113 for means of 1.525 and 17.253, respectively, as well as comparable coefficients of variation between priming with attM and $\exp R^{+} c h$ were calculated for all traits (Table 1). Furthermore, high repeatability between $r^{2}=0.898$ and $r^{2}=0.999$ was calculated for priming with attM and $r^{2}=0.793$ and $r^{2}=0.831$ for priming with $\exp R^{+} c h$, respectively (Table 1$)$.

Out of the lme model, normal distribution and homogeneity of variances were calculated by plotting the standardized residuals (data not shown). Relative susceptibility is a trait calculated out of the relationship of separate scoring for Puccinia hordei (\%) and Puccinia hordei (scores). Significant $(P<0.001)$ effects of priming $\left(\alpha_{i}\right)$, accessions $\left(\beta_{j}\right)$, and the interaction $(\alpha \beta)_{i j}$ were identified for relative susceptibility (Table 2 ). For each accession analyzed, differences between priming with $a t t M$ and $\exp R^{+} c h$ were detected (Fig. 2), as well as significant $(P<0.05)$ differences between the accessions within each variant, i.e., priming with $\operatorname{attM}$ or $\exp R^{+} c h$ (Table 1). Moreover, significant $(P<0.05)$ differences between the accessions considering priming efficiency are shown in Figure 2 by groups a, b, and c. For example, accessions Morex, BCC768, and HOR7985 (group a) showed significantly different priming response than Golden Promise (group b) and BCC436 (group c), whereas BCC1589 and BCC1415 were grouped between, in group bc (Fig. 2). Using the priming efficiency, accessions can be clustered in high and low primable accessions, for instance HOR7985 has a much higher priming efficiency than BCC436 (Fig. 2).

\section{DISCUSSION}

With relative susceptibility, a combination of qualitative (Puccinia hordei scores) and quantitative (Puccinia hordei \%) scoring is enabled, which is relevant for a ranking of the accessions for priming efficiency. Adapting the relative susceptibility, a clear and significant priming effect on resistance toward Puccinia hordei

\begin{tabular}{|c|c|c|c|c|c|c|c|c|}
\hline \multicolumn{9}{|c|}{$\begin{array}{c}\text { TABLE } 1 \\
\text { Statistics and repeatability }\end{array}$} \\
\hline Trait & Priming & $\operatorname{Min}^{a}$ & $\operatorname{Max}^{a}$ & Mean $^{a}$ & $\mathrm{SD}^{\mathrm{a}}$ & $\mathrm{CV}^{\mathrm{a}}$ & $\mathrm{LSD}^{\mathrm{a}}$ & Repeatability \\
\hline & $\exp R^{+} c h$ & 3.00 & 25.00 & 11.84 & 3.821 & 0.323 & 12.045 & 0.831 \\
\hline Puccinia hordei (scores) & attM & 2.25 & 3.00 & 2.63 & 0.242 & 0.092 & 0.054 & 0.999 \\
\hline Relative susceptibility & $\exp R^{+} c h$ & 0.88 & 1.64 & 1.34 & 0.108 & 0.080 & 0.010 & 0.795 \\
\hline
\end{tabular}
was detected in the experiments (Tables 1 and 2, Fig. 2). Thus, the priming, also in comparison with the control treatment (inoculation with $a t t M)$ was very efficient with respect to the resistance against

a Minimum, maximum, mean, standard deviation (SD) in \%, coefficient of variation (CV) (SD divided by mean), and least significant difference (LSD). 
Puccinia hordei. Low standard deviation and high repeatability indicate that the priming method applied is reproducible. Therefore, a reliable and replicable priming system using Ensifer meliloti as the priming trigger was established. In this system barley can be tested for the priming effect on the resistance against the challenger Puccinia hordei. Other priming systems, established for testing the priming effect on the resistance against the challenger Blumeria graminis in barley or Puccinia graminis in wheat, or using chemical AHLs as priming trigger instead of Ensifer meliloti, also revealed priming effects (Hernández-Reyes et al. 2014; Schikora et al. 2011). In all cases, the priming with AHL-producing bacteria or single AHL lead to an increase of resistance or pathogen defense (Viswanath et al. 2016). Also in our study, a lower percentage of diseased leaf area and a reduced sporulation (less susceptible infection types) under priming with $\exp ^{+} c h$ were detected (Table 1, Fig. 2). This effect of induced resistance is unique for oxo-C14HSL, whereas for AHL with acyl chains with lower length, different effects, such as increased root growth in Arabidopsis thaliana was shown (Ortiz-Castro et al. 2008; Schenk et al. 2012).

Besides the single effect of priming, significant differences between the seven analyzed accessions were observed, indicating a differentiated response of barley accessions to priming with Ensifer meliloti toward Puccinia hordei resistance (Tables 1 and 2, Fig. 2), i.e., genotypic differences. This diversity is a prerequisite for the ranking by priming efficiency, which divides the accessions in low and highly primable accessions based on relative susceptibility (Fig. 2 ). With this ranking, a selection of these accessions with highest differences between priming with $a t t M$ and $\exp R^{+} c h$ is possible and facilitates the selection of highly responding accessions for further analyses with regard to resistance mechanisms or priming regulation in plants. Out of the barley Genobar collection, the most diverse ones are BCC436, an accession from China with six-rowed ear type and low priming efficiency, as well as the two-rowed HOR7985 from Turkey showing high priming efficiency (Fig. 2) (Haseneyer et al. 2010). Because of high priming efficiency, Morex is clustered as a well primable accession. Additionally, high values for relative susceptibility for attM control treatment (Fig. 2) were scored for Morex, despite, e.g., the resistance gene $R p h 8$ was mapped in the

TABLE 2

Analysis of variances for relative susceptibility

\begin{tabular}{lrr}
\hline Effect & F value & $P$ value \\
\hline Priming $\left(\alpha_{i}\right)$ & 580.30 & $<0.001$ \\
\hline Accession $\left(\beta_{j}\right)$ & 9.33 & $<0.001$ \\
\hline$(\alpha \beta)_{i j}$ & 7.33 & $<0.001$ \\
\hline
\end{tabular}

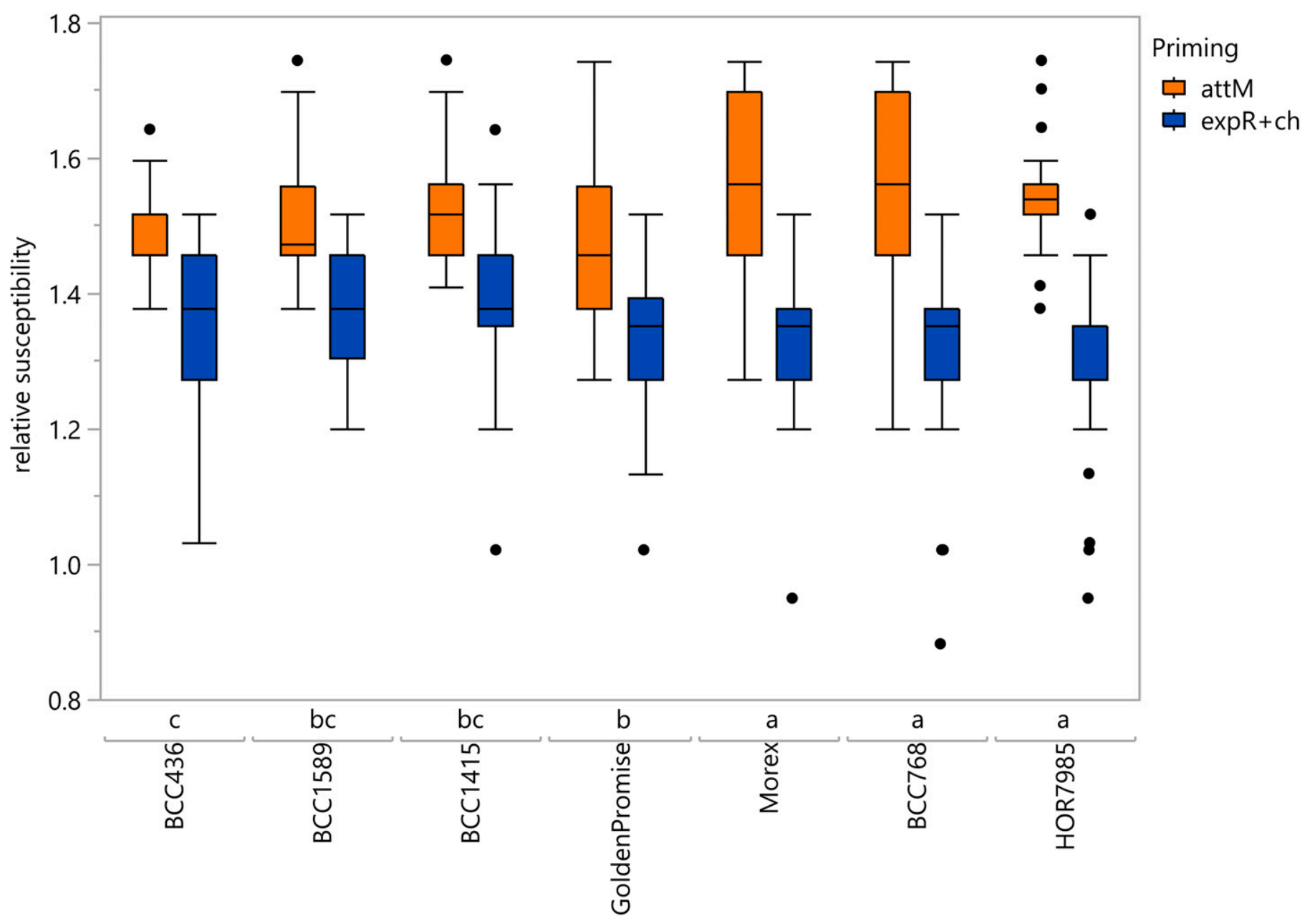

Accessions ordered by priming efficiency (ascending)

Fig. 2. Whisker Box Plots of relative susceptibility for each accession primed with attM (orange) or exp $R^{+} c h$ (blue) bacteria. Accessions are ordered by priming efficiency and significant $(P<0.05)$ differences between accessions are provided in letters a, b, and c. 
Morex reference genome on $5 \mathrm{H}$ at $12.7 \mathrm{Mb}$ (Mascher et al. 2017). This resistance has been overcome by the Puccinia hordei I-80 isolate (Niks et al. 2000), which was used in the present study. Thus, especially pathogen susceptible cultivars could be more efficient in priming related to ISR. There is a trend showing a connection between high relative susceptibility in the attM control treatment and a high priming capacity, i.e., accessions Morex, BCC768, and HOR7985, as well as accessions with low relative susceptibility, such as BCC436, BCC1589, BCC1415, and Golden Promise seem to be primable to a low extent, only (Fig. 2). Maybe accessions with higher relative susceptibility to Puccinia hordei have more potential for priming in comparison with these ones, which have lower susceptibility. This has to be proven in further studies on Ensifer meliloti priming concerning leaf rust response with a larger number of barley accessions. Furthermore, the diversity detected with respect to priming may be used for testing an association panel (Pasam et al. 2012) for priming and conduct genome wide association studies to detect quantitative trait loci involved in priming capacity on resistance to Puccinia hordei.

\section{ACKNOWLEDGMENTS}

We thank C. Hoppe for excellent technical assistance, the PrimedPlant Consortium for close collaboration, and C. Balko for providing seeds of the Genobar collection.

\section{LITERATURE CITED}

Anikster, Y., and Wahl, I. 1979. Coevolution of the rust fungi on Gramineae and Liliaceae and their hosts. Annu. Rev. Phytopathol. 17:367-403.

Beckers, G. J., Jaskiewicz, M., Liu, Y., Underwood, W. R., He, S. Y., Zhang, S., and Conrath, U. 2009. Mitogen-activated protein kinases 3 and 6 are required for full priming of stress responses in Arabidopsis thaliana. Plant Cell 21:944-953.

Cha, C., Gao, P., Chen, Y.-C., Shaw, P. D., and Farrand, S. K. 1998. Production of acyl-homoserine lactone quorum-sensing signals by gram-negative plantassociated bacteria. Mol. Plant-Microbe Interact. 11:1119-1129.

Comadran, J., Kilian, B., Russell, J., Ramsay, L., Stein, N., Ganal, M., Shaw, P., Bayer, M., Thomas, W., Marshall, D., Hedley, P., Tondelli, A., Pecchioni, N., Francia, E., Korzun, V., Walther, A., and Waugh, R. 2012. Natural variation in a homolog of Antirrhinum CENTRORADIALIS contributed to spring growth habit and environmental adaptation in cultivated barley. Nat. Genet. 44:1388-1392

Conrath, U., Beckers, G. J., Flors, V., García-Agustín, P., Jakab, G., Mauch, F., Newman, M.-A., Pieterse, C. M., Poinssot, B., and Pozo, M. J. 2006. Priming: Getting ready for battle. Mol. Plant-Microbe Interact. 19:1062-1071.

Conrath, U., Pieterse, C. M., and Mauch-Mani, B. 2002. Priming in plant-pathogen interactions. Trends Plant Sci. 7:210-216.

Cotterill, P., Rees, R., Platz, G., and Dill-Macky, R. 1992. Effects of leaf rust on selected Australian barleys. Aust. J. Exp. Agric. 32:747-751.

Dracatos, P., Khatkar, M., Singh, D., Stefanato, F., Park, R., and Boyd, L. 2016. Resistance in Australian barley (Hordeum vulgare) germplasm to the exotic pathogen Puccinia striiformis f. sp. hordei, causal agent of stripe rust. Plant Pathol. 65:734-743.

FAOSTAT. 2016. Food and Agriculture Organization of the United Nations. http://faostat.fao.org/en/\#home

García-Fraile, P., Menéndez, E., and Rivas, R. 2015. Role of bacterial biofertilizers in agriculture and forestry. AIMS Bioeng. 2:183-205.

Gower, J. C. 1967. Multivariate analysis and multidimensional geometry. J. Roy. Stat. Soc. D-Sta. 17:13-28.

Han, S., Li, D., Trost, E., Mayer, K. F., Vlot, A. C., Heller, W., Schmid, M., Hartmann, A., and Rothballer, M. 2016. Systemic responses of barley to the 3-hydroxy-decanoyl-homoserine lactone producing plant beneficial endophyte Acidovorax radicis N35. Front. Plant Sci. 7:1868.

Haseneyer, G., Stracke, S., Paul, C., Einfeldt, C., Broda, A., Piepho, H. P., Graner, A., and Geiger, H. 2010. Population structure and phenotypic variation of a spring barley world collection set up for association studies. Plant Breed. 129:271-279.
Hernández-Reyes, C., Schenk, S. T., Neumann, C., Kogel, K. H., and Schikora, A. 2014. N-acyl-homoserine lactones-producing bacteria protect plants against plant and human pathogens. Microbiol. Biotechnol. 7:580-588.

Kaufman, L., and Rousseeuw, P. J. 2005. Finding Groups in Data: An Introduction to Cluster Analysis vol 603. Probability and Statistics. John Wiley \& Sons, Inc., Hoboken, NJ.

Kavanagh, P. J., Singh, D., Bansal, U. K., and Park, R. F. 2017. Inheritance and characterization of the new and rare gene $R p h 25$ conferring seedling resistance in Hordeum vulgare against Puccinia hordei. Plant Breed. 136:908-912.

Levine, M. N., and Cherewick, W. J. 1952. Studies on dwarf leaf rust of barley, Vol. 1051. U.S. Department of Agriculture.

Liu, F., Bian, Z., Jia, Z., Zhao, Q., and Song, S. 2012. The GCR1 and GPA1 participate in promotion of Arabidopsis primary root elongation induced by $\mathrm{N}$-acyl-homoserine lactones, the bacterial quorum-sensing signals. Mol. Plant-Microbe Interact. 25:677-683.

Lohitha, S., Bhaskara, R., Sivaprasad, Y., Prathyusha, M., Sujitha, A., and Krishna, T. 2016. Molecular characterization and antagonistic potential of phenazine-1-carboxylic acid producing Pseudomonas fluorescens isolates from economically important crops in South India. Int J Clin Biol Sci 1:30-40.

Martinez-Medina, A., Flors, V., Heil, M., Mauch-Mani, B., Pieterse, C. M., Pozo, M. J., Ton, J., van Dam, N. M., and Conrath, U. 2016. Recognizing plant defense priming. Trends Plant Sci. 21:818-822.

Mascher, M., Gundlach, H., Himmelbach, A., Beier, S., Twardziok, S. O., Wicker, T., Radchuk, V., Dockter, C., Hedley, P. E., Russell, J., Bayer, M., Ramsay, L., Liu, H., Haberer, G., Zhang, X.-Q., Zhang, Q., Barrero, R. A., Li, L., Taudien, S., Groth, M., Felder, M., Hastie, A., Šimková, H., Staňková, H., Vrána, J., Chan, S., Muñoz-Amatriaín, M., Ounit, R., Wanamaker, S., Bolser, D., Colmsee, C., Schmutzer, T., Aliyeva-Schnorr, L., Grasso, S., Tanskanen, J., Chailyan, A., Sampath, D., Heavens, D., Clissold, L., Cao, S., Chapman, B., Dai, F., Han, Y., Li, H., Li, X., Lin, C., McCooke, J. K., Tan, C., Wang, P., Wang, S., Yin, S., Zhou, G., Poland, J. A., Bellgard, M. I., Borisjuk, L., Houben, A., Doležel, J., Ayling, S., Lonardi, S., Kersey, P., Langridge, P., Muehlbauer, G. J., Clark, M. D., Caccamo, M., Schulman, A. H., Mayer, K. F. X., Platzer, M., Close, T. J., Scholz, U., Hansson, M., Zhang, G., Braumann, I., Spannagl, M., Li, C., Waugh, R., and Stein, N. 2017. A chromosome conformation capture ordered sequence of the barley genome. Nature 544:427-433.

Mathesius, U., Mulders, S., Gao, M., Teplitski, M., Caetano-Anollés, G., Rolfe, B. G., and Bauer, W. D. 2003. Extensive and specific responses of a eukaryote to bacterial quorum-sensing signals. Proc. Natl. Acad. Sci. 100: 1444-1449.

Mauch-Mani, B., Baccelli, I., Luna, E., and Flors, V. 2017. Defense priming: An adaptive part of induced resistance. Annu. Rev. Plant Biol. 68:485-512.

Mauch-Mani, B., and Mauch, F. 2005. The role of abscisic acid in plant-pathogen interactions. Curr. Opin. Plant Biol. 8:409-414.

Mhlongo, M., Piater, L. A., Madala, N. E., Labuschagne, N., and Dubery, I. A. D. 2018. The chemistry of plant-microbe interactions in the rhizosphere and the potential for metabolomics to reveal signaling related to defense priming and induced systemic resistance. Front. Plant Sci. 9:112.

Moll, E., Flath, K., and Piepho, H. 2000. Die Prüfung von Pflanzen auf ihre Widerstandsfähigkeit gegen Schadorganismen in der Biologischen Bundesanstalt Teil 3: Methodische Anleitung zur Bewertung der partiellen Resistenz von Getreidesortimenten und die SAS-Applikation RESI Mitteilungen aus der Biologischen Bundesanstalt für Land-und Forstwirtschaft; Testing of crop cultivars for resistance to noxious organisms at the Federal Biological Research Centre Part 3: Methodical guidelines for the assessment of partial resistance in cereal cultivars and the SAS Application RESI, Vol. 374. Mitteilungen aus der Biologischen Bundesanstalt für Land-und Forstwirtschaft Biologischen Bundesanstalt für Land-und Forstwirtschaft Braunschweig und Berlin, Parey Buchverlag Berlin, Berlin-Dahlem.

Murray, G., and Brennan, J. 2010. Estimating disease losses to the Australian barley industry. Australas. Plant Pathol. 39:85-96.

Newman, M.-A., Dow, J. M., Molinaro, A., and Parrilli, M. 2007. Invited review: Priming, induction and modulation of plant defense responses by bacterial lipopolysaccharides. J. Endotoxin Res. 13:69-84.

Niks, R., Walther, U., Jaiser, H., Matinez, F., and Rubiales, D. 2000. Resistance against barley leaf rust (Puccinia hordei) in West-European spring barley germplasm. Agronomie 20:769-782.

Ortiz-Castro, R., Martinez-Trujillo, M., and Lopez-Bucio, J. 2008. N-acyl-Lhomoserine lactones: A class of bacterial quorum-sensing signals alter postembryonic root development in Arabidopsis thaliana. Plant Cell Environ. 31:1497-1509. 
Pang, Y., Liu, X., Ma, Y., Chernin, L., Berg, G., and Gao, K. 2009. Induction of systemic resistance, root colonisation and biocontrol activities of the rhizospheric strain of Serratia plymuthica are dependent on N-acyl homoserine lactones. Eur. J. Plant Pathol. 124:261-268.

Park, R. F., Golegaonkar, P. G., Derevnina, L., Sandhu, K. S., Karaoglu, H., Elmansour, H. M., Dracatos, P. M., and Singh, D. 2015. Leaf rust of cultivated barley: Pathology and control. Annu. Rev. Phytopathol. 53:565-589.

Parsek, M. R., and Greenberg, E. P. 2000. Acyl-homoserine lactone quorum sensing in gram-negative bacteria: A signaling mechanism involved in associations with higher organisms. Proc. Natl. Acad. Sci. 97:8789-8793.

Pasam, R. K., Sharma, R., Malosetti, M., van Eeuwijk, F. A., Haseneyer, G., Kilian, B., and Graner, A. 2012. Genome-wide association studies for agronomical traits in a world-wide spring barley collection. BMC Plant Biol. $12: 16$.

Pieterse, C. M., Zamioudis, C., Berendsen, R. L., Weller, D. M., Van Wees, S. C., and Bakker, P. A. 2014. Induced systemic resistance by beneficial microbes. Annu. Rev. Phytopathol. 52:347-375.

Reif, J. C., Melchinger, A. E., and Frisch, M. 2005. Genetical and mathematical properties of similarity and dissimilarity coefficients applied in plant breeding and seed bank management. Crop Sci. 45:1-7.

Reynolds, A. P., Richards, G., de la Iglesia, B., and Rayward-Smith, V. J. 2006. Clustering rules: A comparison of partitioning and hierarchical clustering algorithms. J. Math. Model. Algorithms 5:475-504.

RStudio Team. 2015. RStudio: Integrated development for R. RStudio, Inc., Boston, MA. https://www.rstudio.com/

Schenk, S. T., Hernández-Reyes, C., Samans, B., Stein, E., Neumann, C., Schikora, M., Reichelt, M., Mithöfer, A., Becker, A., and Kogel, K.-H. 2014. $\mathrm{N}$-acyl-homoserine lactone primes plants for cell wall reinforcement and induces resistance to bacterial pathogens via the salicylic acid/oxylipin pathway. Plant Cell 26:2708-2723.

Schenk, S. T., and Schikora, A. 2015. AHL-priming functions via oxylipin and salicylic acid. Front. Plant Sci. 5:784.

Schenk, S. T., Stein, E., Kogel, K.-H., and Schikora, A. 2012. Arabidopsis growth and defense are modulated by bacterial quorum sensing molecules. Plant Signal. Behav. 7:178-181.

Schikora, A., Schenk, S. T., and Hartmann, A. 2016. Beneficial effects of bacteria-plant communication based on quorum sensing molecules of the N-acyl homoserine lactone group. Plant Mol. Biol. 90:605-612.

Schikora, A., Schenk, S. T., Stein, E., Molitor, A., Zuccaro, A., and Kogel, K.-H. 2011. N-acyl-homoserine lactone confers resistance toward biotrophic and hemibiotrophic pathogens via altered activation of AtMPK6. Plant Physiol. 157:1407-1418.

Schuhegger, R., Ihring, A., Gantner, S., Bahnweg, G., Knappe, C., Vogg, G., Hutzler, P., Schmid, M., Van Breusegem, F., and Eberl, L. 2006. Induction of systemic resistance in tomato by N-acyl-L-homoserine lactone-producing rhizosphere bacteria. Plant Cell Environ. 29:909-918.

Silvar, C., Casas, A., Kopahnke, D., Habekuß, A., Schweizer, G., Gracia, M., Lasa, J., Ciudad, F., Molina-Cano, J., and Igartua, E. 2010. Screening the Spanish barley core collection for disease resistance. Plant Breed. 129:45-52.

Singh, D., Dracatos, P., Derevnina, L., Zhou, M., and Park, R. F. 2015. Rph23: A new designated additive adult plant resistance gene to leaf rust in barley on chromosome 7H. Plant Breed. 134:62-69.
Singh, D., Dracatos, P., Loughman, R., and Park, R. 2017. Genetic mapping of resistance to Puccinia hordei in three barley doubled-haploid populations. Euphytica 213:16.

Singh, S., Pathak, R., and Choudhary, V. 2016. Plant growth-promoting rhizobacteria-mediated acquired systemic resistance in plants against pests and diseases. Pages 125-134 in: Microbial-Mediated Induced Systemic Resistance in Plants.D. K. Choudhary and A. Varma, eds. Springer Science+Business Media, Singapore.

Stein, E., and Schikora, A. 2018. Detection of Bacterial Quorum Sensing Molecules. Pages 171-179 in: Host-Pathogen Interactions. Springer.

Viswanath, G., Jegan, S., Baskaran, V., Kathiravan, R., and Prabavathy, V. R. 2015. Diversity and N-acyl-homoserine lactone production by Gammaproteobacteria associated with Avicennia marina rhizosphere of South Indian mangroves. Syst. Appl. Microbiol. 38:340-345.

Viswanath, G., Sekar, J., and Prabavathy, V. 2016. Acyl homoserine lactoneproducing rhizobacteria elicit systemic resistance in plants. Pages 135-146 in: Microbial-Mediated Induced Systemic Resistance in Plants. D. K. Choudhary and A. Varma, eds. Springer Science+Business Media, Singapore.

von Rad, U., Klein, I., Dobrev, P. I., Kottova, J., Zazimalova, E., Fekete, A., Hartmann, A., Schmitt-Kopplin, P., and Durner, J. 2008. Response of Arabidopsis thaliana to N-hexanoyl-DL-homoserine-lactone, a bacterial quorum sensing molecule produced in the rhizosphere. Planta 229:73-85.

Wright, S. 1968. Evolution and the Genetics of Populations: Genetic and Biometric Foundations vol 1. Evolution and the Genetics of Populations: A Treatise. University of Chicago Press, Chicago.

Yu, X., Kong, H. Y., Meiyalaghan, V., Casonato, S., Chng, S., Jones, E. E., Butler, R. C., Pickering, R., Johnston, P. A. J. T., and Genetics, A. 2018. Genetic mapping of a barley leaf rust resistance gene Rph26 introgressed from Hordeum bulbosum. Theor. Appl. Genet. 131:2567-2580.

Zarkani, A. A., Stein, E., Röhrich, C. R., Schikora, M., Evguenieva-Hackenberg, E., Degenkolb, T., Vilcinskas, A., Klug, G., Kogel, K.-H., and Schikora, A. 2013. Homoserine lactones influence the reaction of plants to rhizobia. Int. J. Mol. Sci. 14:17122-17146.

Zhalnina, K., Louie, K. B., Hao, Z., Mansoori, N., da Rocha, U. N., Shi, S., Cho, H., Karaoz, U., Loqué, D., and Bowen, B. P. 2018. Dynamic root exudate chemistry and microbial substrate preferences drive patterns in rhizosphere microbial community assembly. Nat. Microbiol. 3:470-480.

Zhao, Q., Zhang, C., Jia, Z., Huang, Y., Li, H., and Song, S. 2015. Involvement of calmodulin in regulation of primary root elongation by N-3-oxo-hexanoyl homoserine lactone in Arabidopsis thaliana. Front. Plant Sci. 5:807.

Ziems, L., Franckowiak, J., Platz, G., Mace, E., Park, R., Singh, D., Jordan, D., and Hickey, L. 2017a. Investigating successive Australian barley breeding populations for stable resistance to leaf rust. Theor. Appl. Genet. 130: 2463-2477.

Ziems, L. A., Hickey, L. T., Platz, G. J., Franckowiak, J. D., Dracatos, P. M., Singh, D., and Park, R. F. 2017b. Characterization of Rph24: A gene conferring adult plant resistance to Puccinia hordei in barley. Phytopathology 107:834-841.

Zimmerli, L., Jakab, G., Métraux, J.-P., and Mauch-Mani, B. 2000. Potentiation of pathogen-specific defense mechanisms in Arabidopsis by $\beta$-aminobutyric acid. Proc. Natl. Acad. Sci. 97:12920-12925. 